\title{
Invasive, minimally invasive and non-invasive hemodynamic monitoring in perioperative medicine
}

\begin{abstract}
The hemodynamic monitoring is a fundamental part of the patient in the perioperative period, during the last decade the monitoring at the patient's bedside has grown at giant steps, from the emergency area, operating room, to the Intensive Care area. One of its most important advances is the decrease in the use of pulmonary artery catheter, which is being replaced by ultrasound and less invasive monitoring techniques, in this article we will review from the beginning of the monitoring to the most used less invasive monitors currently.
\end{abstract}

Keywords: Hemodynamic monitoring, pulse wave contour analysis, transpulmonarythermodilution, pulse pressure variation, systolic volume variability, arterial elastance, ultrasound, bioreactance, estimated continuous cardiac output
Volume I2 Issue I - 2020

\author{
Guerrero Gutiérrez Manuel Alberto,' \\ Pérez Nieto Orlando Rubén, ${ }^{2}$ Eder Iván \\ Zamarrón López, ${ }^{3}$ Jesús Salvador Sánchez \\ Díaz, ${ }^{4}$ Escarramán Martínez Diego, ${ }^{5}$ Ernesto \\ Deloya Tomás, ${ }^{2}$ Lizbeth Franco Morales, ${ }^{2}$ \\ Luis Antonio Morgado Villaseñor, ${ }^{6}$ Martínez \\ Camacho Miguel Ángel, ${ }^{7}$ Soriano Orozco \\ Raúl, ${ }^{6}$ Diaz Martínez Manuel Alfredo ${ }^{8}$ \\ '3rd year Anesthesia resident IMSS Specialty Hospital, National \\ Medical Center “La Raza”, Mexico \\ ${ }^{2}$ Intensive Care Doctor, General Hospital, San Juan del Rio, \\ Mexico. \\ ${ }^{3}$ Intensive Care Doctor, IMSS HGSZ No. 26, CEMAIN Hospital, \\ Mexico \\ 4Intensive Care Doctor, General Hospital PEMEX Veracruz. \\ IMSS UMAE 189, Mexico \\ ${ }^{5}$ Anesthesia Doctor, IMSS Specialty Hospital, National Medical \\ Center "La Raza", Mexico \\ ${ }^{6}$ Intensivist, UMAE IMSS, Mexico \\ ${ }^{7}$ Physiotherapist, University of Querétaro, México \\ ${ }^{8}$ Resident in Anesthesia in General hospital "Doctor Salvador \\ González Herrejon”, México
}

Correspondence: Guerrero Gutiérrez Manuel Alberto, 3rd year Anesthesia resident IMSS Specialty Hospital, National Medical Center "La Raza”, Mexico,

Email Manuelguerrerom@gmail.com

Received: November 20, 2019 | Published: January 09, 2020

\section{Introduction}

The word monitoring comes from the Latin, from monere meaning warning, remembering or admonishing, in our case it is the monitoring of parameters and hemodynamic variables. ${ }^{1}$ There are a number of 230 million surgeries performed in the world annually, from low, intermediate and high cardiovascular risks, $15 \%$ of these procedures are from high-risk patients, where it is important to choose the type of monitoring to be offered to the patient and not about invading the patient or underestimating their basic pathology, surgery to be performed, ideally individualizing each patient and remembering that there is no "ideal monitoring for all patients" is a very important decision on the part of the clinician. ${ }^{2,3}$

During the last decade, hemodynamic monitoring has evolved considerably, from the emergency area, operating room, intensive care unit. ${ }^{4}$ The greatest impact in their evolution is the decreasing use of the Pulmonary Artery Catheter (PAC), together with the advent of minimally invasive monitoring and non-invasive Cardiac Exit monitors, which have been shown to offer hemodynamic variables with algorithm creations that will guide us towards decision making, without the high invasion of a CAP, the transpulmonary thermo dilution that these two last count on precise indications at present. ${ }^{5,6}$ In this article we will review from Invasive, moderately invasive, minimally invasive and non-invasive monitoring, analyzing the advantages offered by each of them, as well as the review of algorithms to facilitate decision-making during the invasion and with the hemodynamic variables available.

\section{Invasive hemodynamic monitoring}

\section{Pulmonary Artery Catheter}

The Pulmonary Artery Catheter (PAC) has currently exceeded the area of cardiology being placed in all critical areas of the hospital, this being the gold standard to date. his indications are currently very controversial, as is the patient with severe insufficiency respiratory syndrome that patient who does not respond with the initial monitoring, the variables offered by the PAC are: Cardiac Output (CO), pressure of occlusion of the pulmonary artery (PAOP), pulmonary capillary pressure (PCP), Venous blood saturation $\left(\mathrm{SCVO}_{2}\right)$, however, the complications that this type of catheter has to overcome outweigh the rest (Table 1$)^{7}$

In 2013 the Paul E. Marik, published a study based on a data collection from 1970 to 2013, and calls it the Obituary where it shows that the pulmonary artery catheter, presents an inaccuracy in the measurement of cardiac output of the 25 to $30 \%$, it is difficult to place and corroborate their placement, increases unnecessary risks, bad measurements, therefore poor decisions, on critical patient invasion, increased costs and there is no evidence to improve morbidity and mortality. ${ }^{8}$ 
Table I Risks in the placement of the pulmonary artery catheter

\begin{tabular}{l} 
Complications of catheterization to the pulmonary artery \\
\hline Pulmonary Hemorrhage, Arterial Rupture. \\
Right atrium Thrombosis, arterial thrombosis, jugular or subclavian vein thrombosis. \\
Intra-arterial node, Catheter-related infection, Endocarditis. \\
Atrial and ventricular arrhythmias, Electromechanical dissociation. \\
Air embolism
\end{tabular}

\section{Moderately invasive hemodynamic monitoring}

Transpulmonary thermodilution and pulse wave contour analysis

This type of monitoring was born at the beginning of the 70 s with Mark Lennon. ${ }^{9}$ They create an algorithm based on arterial ventricular coupling in the analysis of the pulse wave and the thermodilution, in order to obtain the cardiac output and its derived variables, applying dilution indicators based on the principle of temperature changes in the time (Figure 1).
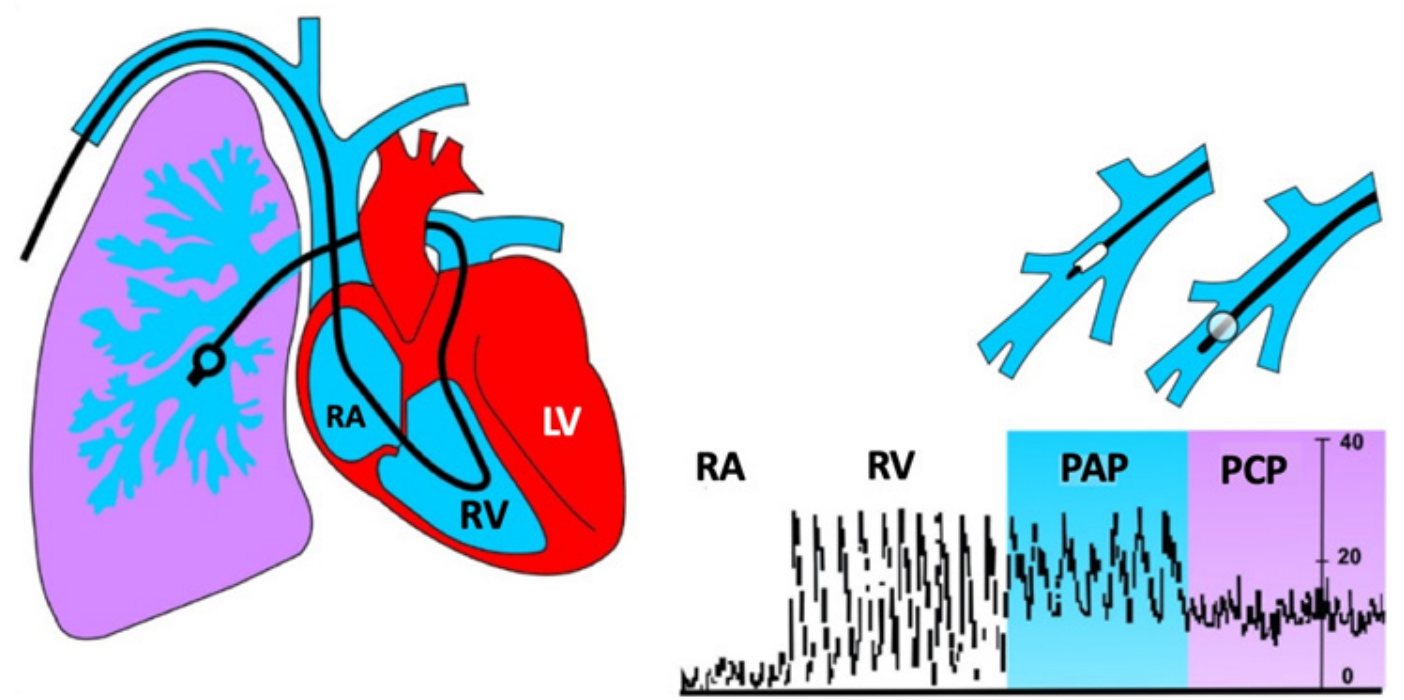

Figure I Pressures recorded during the placement of a flow-guided catheter. $\mathrm{RA}$, right atrial pressure; RV, right ventricular pressure; PAP, pulmonary artery pressure; PCP, pulmonary capillary pressure; LV, Left ventricle.

The transpulmonary thermodilution monitors (PICCO, Volume View), are less invasive than the pulmonary artery catheter (does not pass through the heart), but require the insertion of a central venous catheter and an arterial thermistor (femoral), offering the following variables: Cardiac Output, Diastolic Tele Volume, Cardiac Index, Extravascular Lung Water (EVLW), Vascular Permeability Index, Systolic Volume Variability, remembering that it requires frequent calibration.

Transpulmonary thermodilution monitors (PICCO, Volume View), are less invasive than the pulmonary artery catheter (does not pass through the heart), but require the insertion of a central venous catheter and an arterial thermistor (femoral), offering the following variables: Cardiac Output, Diastolic Tele Volume, Cardiac Index, Extravascular Lung Water (EVLW), Vascular Permeability Index, Systolic Volume Variability, remembering that it requires frequent calibration.

A retrospective review of transpulmonary thermodilution, reporting a GC similar to that of the pulmonary artery catheter, their measurements are not reliable in GC less than $2 \mathrm{~L} / \mathrm{min}$, their errors in the technique arrive to affect the measurement, does not measure the GC continuously, it does so intermittently, so it does not serve to respond to volume and in the critical patient must be calibrated at least every hour. ${ }^{10}$

\section{Central venous pressure}

The Frank-Starling law, a benefit that arises from the experiment of this both was the filling pressure of the Right Auricle, now known as the Central Venous Pressure (PVC), in this study, it is related that the number offered by the PVC is directly proportional to the capacity to respond to volume. ${ }^{11,12}$ In 2018 De Backer and JL Vincent, in the journal of Critical Care publishes a review study with an expert point of view, where they reach the conclusions that it is the most used resuscitation variable in the world, it offers multiple limitations, but it should not be abandoned for these reasons: Its curve contributes a lot to the patient with heart disease and the critical patient (Figure 2), in addition to that we must evaluate its tendency and it serves as a limit to not reanimate the patient more, seeing its benefits and contras (Table 2). ${ }^{13}$ 

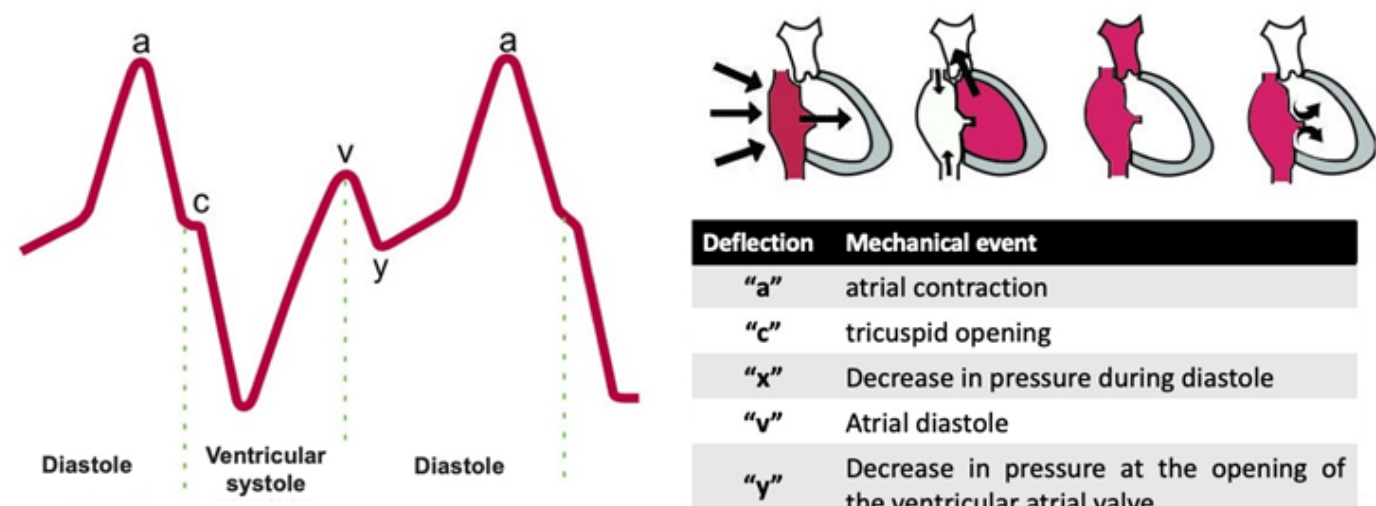

Deflection Mechanical event

"a" atrial contraction

"c" tricuspid opening

" $\mathrm{x}$ " Decrease in pressure during diastole

"v" Atrial diastole

" $y$ " Decrease in pressure at the opening of the ventricular atrial valve

Figure 2 Central venous pressure curve.

Table 2 Benefits and disadvantages of measuring Central Venous Pressure

\begin{tabular}{|c|c|c|}
\hline Variables & Pros & Cons \\
\hline Measures & $\begin{array}{l}\text { Easy to measure } \\
\text { Minimum of appliances } \\
\text { Economic }\end{array}$ & $\begin{array}{l}\text { Error in measurements } \\
\text { Influence of the MV } \\
\text { Influence of the PIA }\end{array}$ \\
\hline $\begin{array}{l}\text { CVP in response to } \\
\text { fluid therapy }\end{array}$ & $\begin{array}{l}\text { The predictive value at the end } \\
\text { is satisfactory as safety margin is } \\
\text { below } 6\end{array}$ & $\begin{array}{l}\text { Its predictive value in response to } \\
\text { fluids is low compared to more } \\
\text { hemodynamic variables. }\end{array}$ \\
\hline $\begin{array}{l}\text { CVP in mechanical } \\
\text { ventilation }\end{array}$ & $\begin{array}{l}\text { The CVP represents the pressure of } \\
\text { the extrathoracic organs }\end{array}$ & $\begin{array}{l}\text { The CVP has failures during its } \\
\text { measurement during the MV. }\end{array}$ \\
\hline $\begin{array}{l}\text { CVP as a marker to } \\
\text { fluid response therapy }\end{array}$ & $\begin{array}{l}\text { An increase in PVC indicates an } \\
\text { increase in Preload. }\end{array}$ & $\begin{array}{l}\text { The increase in PVC indicates an } \\
\text { increase in preload, but it is not } \\
\text { related to the response to fluids. }\end{array}$ \\
\hline
\end{tabular}

\section{Transesophageal ultrasound}

Transesophageal ultrasound is considered a moderately invasive monitoring method. It consists of the use of a probe equipped with an ultrasound transducer at its tip that, once introduced into the esophagus or stomach, allows a direct visualization of the great vessels and the heart, providing information hemodynamic and functional real-time cardiovascular system. ${ }^{14,15}$

With the ETE probe, the following movements can be made: advance or remove it from the esophagus, lateralize to the left or right, rotate it by turning it to the right or left of the patient, anteroflexion movements by flexing the probe forward or backward Flexion by flexing it backwards, and rotating the transducer axis from 0 to 180 degrees. The probe can be inserted at different levels or planes: upper esophagus (ES) $(20-25 \mathrm{~cm}$ from the dental arch), middle esophagus (MS) $(30-40 \mathrm{~cm})$, transgastric (TG) $(40-45 \mathrm{~cm})$ and deep transgastric $(45-50 \mathrm{~cm})$, and in each plane different echocardiographic images can be obtained. The American Society of Echocardiography (ASE), together with the Society of Cardiovascular Anesthesiology (SCA), published recommendations guidelines for the completion of the ETE, establishing twenty standards of heart and major vessel cuts. These 20 images are collected globally (Figure 3). With the projections obtained by transesophageal ultrasound can obtain hemodynamic variables and make decisions, the variables offered by the TTECOCG son: CO: SVxHR (Systolic Volume by Heart Rate), ratio E/e premium correlating with a systolic function of the left ventricle, E/A evaluating the LV diastolic function, Pulmonary Artery Systolic Pressure, TAPSE, MAPSE, LV Ejection Fraction, all this dynamically and in a time of 10 minutes by a physician trained in ultrasound, offering good levels of evidence (Table 3). One of the major limitations of ultrasound is that in order to be considered a basic level sonographer, 150 echocardiograms are required under the supervision of an expert, in this case the expert is the cardiologist. ${ }^{16}$

\section{Consensus recommendations on hemodynamic monitoring and shock 2014}

The 2014 panel of experts in the area of monitoring, with Maurizio Cecconi and collaborators, recommends goals and objectives based on the literature and level of evidence, which are most relevant in our field are: ${ }^{17}$ (1 B).

1. Do not use PVC or POAP to guide resuscitation in fluid therapy.

2. Always use more than one variable Hemodynamics to guide our water management. (Point of good clinical practice).

3. They recommend using dynamic variables on static variables (see Table 4) and when in doubt apply a liquid challenge. (1 B). 


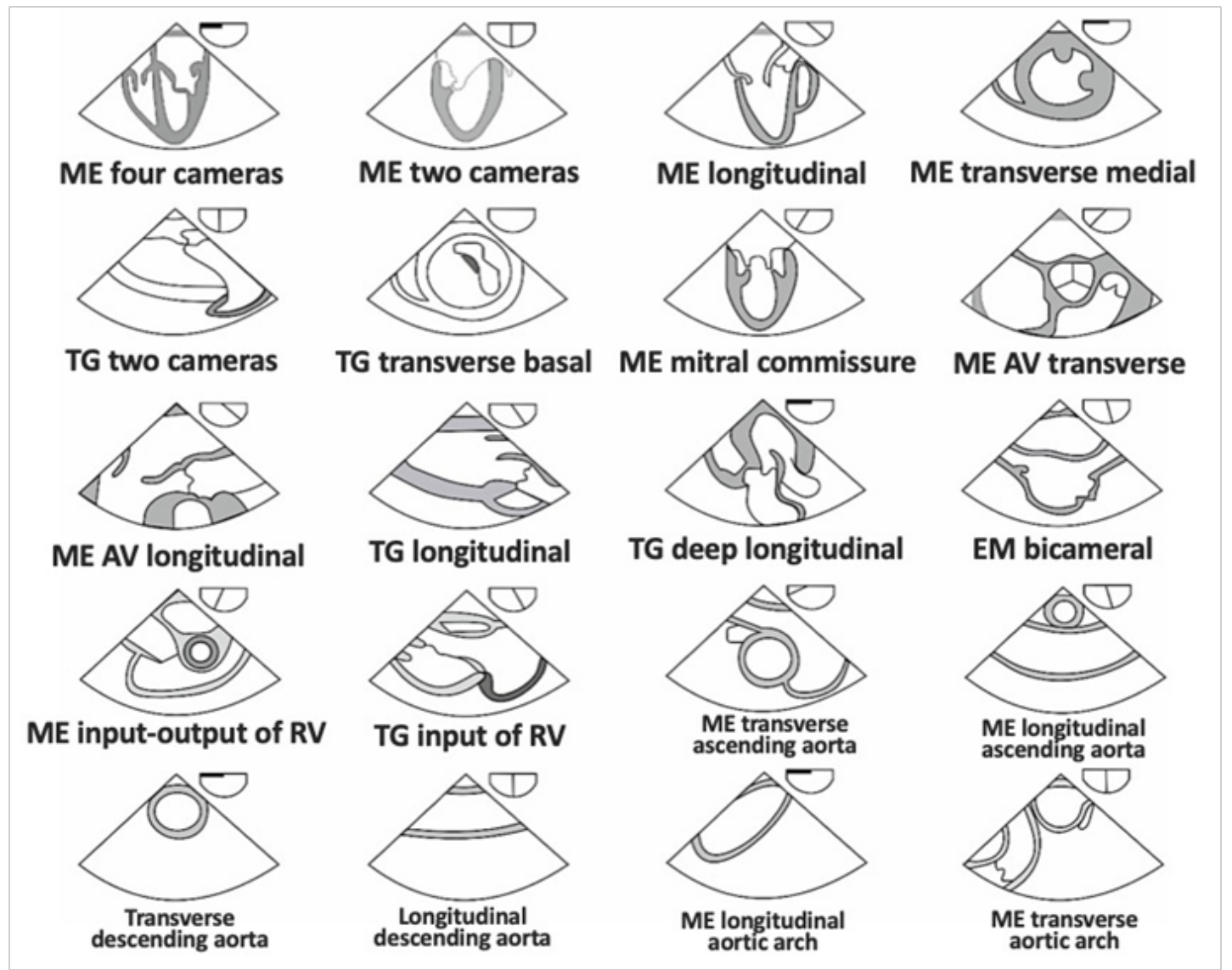

Figure 320 recommended images to be performed by ASE, ES, Upper Esophagus; MS, Middle esophagus;TG, Transgastric. Taken from Revista Brasileira de Anestesiología Vol. 6I, No 4, July-August, 201 I.

Table 3 Summary of the levels of evidence with echocardiographic monitoring, taken from the 2015 ASE Guidelines

\begin{tabular}{lll}
\hline Clinical scenario & Monitoring & Level of evidence \\
\hline Heart failure & ECOCGTT & B2 \\
Critical care & ECOCGTT & B2 \\
Trauma & ECOCGTT/ECOCGTE & D1 \\
Tamponade & ECOCGTT & B2 \\
Pulmonary embolism & ECOCGTT & B2 \\
Thrombosed Prosthetic Valves & ECOCG/ECOCGTE & B2 \\
Kidney/Liver/Pulmonary Transplant & ECOCGTE & Kidney B3 \\
& & Liver B2 \\
& & Pulmonary B2 \\
MajorVascular Surgery & ECOCGTE & B2 \\
Neurosurgery & ECOCGTE & B2 \\
\hline
\end{tabular}


Table 4 Static and dynamic variables to predict volume response. *Result of the measurement of the thoracic transit time of the CO measured with an arterial catheter

\begin{tabular}{|c|c|}
\hline Static variables & Dynamic variables \\
\hline CVP less than $5 \mathrm{mmHg}$ (in $80 \%$ of casses) (IC) & $\begin{array}{l}\text { Passive legs raising with and increase in cardiac output (PiCCO, } \\
\text { echocardiogram) } \\
>10 \%\end{array}$ \\
\hline POAP $<15 \mathrm{mmHg}$ & $P P V>10-15$ \\
\hline TDGV $<600 \mathrm{~mL} / \mathrm{m}^{2}$ & $S V V>10-15$ \\
\hline Total intrathoracic thermal volume $*<850 \mathrm{~mL} / \mathrm{m}^{2}$ & $* \mid 4 \%$ to IP $>1$ \\
\hline \multirow[t]{3}{*}{$\begin{array}{l}\text { Mini fluid challenge, with } 125 \mathrm{~mL} \text { of crystalloids, with minimal } \\
\text { changes in CVP when is less than } 5 \mathrm{mmHg}\end{array}$} & $\begin{array}{l}\text { Collapse Index ICV > 50\% without MV or Distensibility Index of ICV > } 12 \% \\
\text { with MV }\end{array}$ \\
\hline & $\begin{array}{l}\text { Collapse Index of IYV > 50\% without MV or Distensibility Index of IYV > } \\
\text { I } 2 \% \text { with MV }\end{array}$ \\
\hline & $\begin{array}{l}\text { Mini fluid challenge, with } 125 \mathrm{~mL} \text { of crystalloids with raise of cardiac output } \\
>10 \%\end{array}$ \\
\hline
\end{tabular}

CVP, central venous pressure; POAP, occlusion pressure of the pulmonary artery; TDGV, final end-diastolic volume; VPP, pulse pressure variability; VVS, systolic volume variability; IVP, index of plethysmographic variability; IP, perfusion index; VCI, inferior vena cava; VYI, internal jugular vein; GC, cardiac output; VM, mechanical ventilation. ${ }^{18}$

\section{Minimally invasive hemodynamic monitoring}

In the face of abstract thinking in solving problems, our initiative should be based on these questions: What do I need it for? What will I get from it? How many Hemodynamic Variables do I get? and I am going to base my handling with this?, this must be the attitude that we take before the invasion, in this case the taking of an arterial line to guide our management based on goals for minimum invasion, it is necessary to add that the taking of the line arterial should not delay the start of the surgical act and is not safe, the cover of Intensive Care medicine in 2018 published a series of cases where up to $8 \%$ was observed ischemia of the area, even with an Allen test less than 6 seconds, the ischemia subsided after the removal of the arterial catheter. Next, we will mention the variables obtained by taking an arterial line. ${ }^{19}$

\section{Pulse Pressure Variability (PPV) and Systolic Volume Variability (VVS)}

The principles of VPP and VVS are based on the changes in left ventricular volume ejection, with the base of increase in inspiration and decrease in expiration in the patient with Mechanical Ventilation Controlled with Positive Pressure at the end of expiration. ${ }^{20,21}$ Let's explain this in more detail; In inspiration there is an increase in intrathoracic pressure that affects the Right Ventricle (RV) decreasing its preload, which affects the systolic volume of the RV due to alterations in the venous return. Once the fluid passes, this first barrier enters the pulmonary circulation, subsequently passing to the LV, increasing the preload and, therefore, the stroke volume, all this in the inspiratory phase (Figure 4). Being inversely proportional in the expiratory phase, decreasing the volume in the expiratory phase, it should be added that it is not exempt from limitations at the time of its interpretation (Table 5). ${ }^{22}$ The variability that occurs during this inspiratory-expiratory cycle, ${ }^{23,24}$ with a cut-off point of both of 10 $15 \%,{ }^{25}$ is represented by the Frank-Starling Curve, which is explained below.

\section{Coupling of cardiac function curve and venous return}

Cardiac Expenditure results from the interaction of two overlapping curves: cardiac function (Frank's and Starling's law) and RV. Two pumps in series, one central (heart pump) and another peripheral (venous return). The dysfunction of some of them alters the functioning of the other. In the Venous Return curve as the Diastolic Blood Pressure decreases, the Venous Return is maximum and the Cardiac Expenditure increases, in the curve of cardiac function as the PAD increases, the preload increases and the CG increases. The PAD that generates an adequate RV and an adequate cardiac contractility, determines that the CG is regulated by one or another curve. The exact point where these curves cross is optimal (flat part or slope of each one) (Figure 5). This assessment determines the therapeutic strategy, based mainly on the administration of volume or inotropic drugs. ${ }^{18}$

\section{Frank-starling curve}

From the original study by Ernest Starling and Otto Frank, we can obtain an XY curve (Figure 6), which offers us even more knowledge about the response to volume, with the constants of preload and stroke volume, this constant being called Volume Variability Systolic (VVS), represented with a percentage, depending on the variability between these 2 constants, the preload represented by the venous return that is the volume capacitance of this circulatory system, ${ }^{26,27}$ it should be remembered that $70 \%$ of the intravascular volume is found in the veins, and the Systolic Volume which is the volume of blood that the heart expels towards the aorta or the pulmonary artery during the contraction period, representing a cut-off point of the VVS of $10-15 \%,{ }^{28}$ therefore it is not a law for the patient to respond to volume, remembering that fluid therapy is not harmless, it presents direct damage to the glycocaly ${ }^{29}$ and to the circulatory economy if the percentage of variability is very high, it could be a response to other therapies $^{30}$ that we will discuss later. 

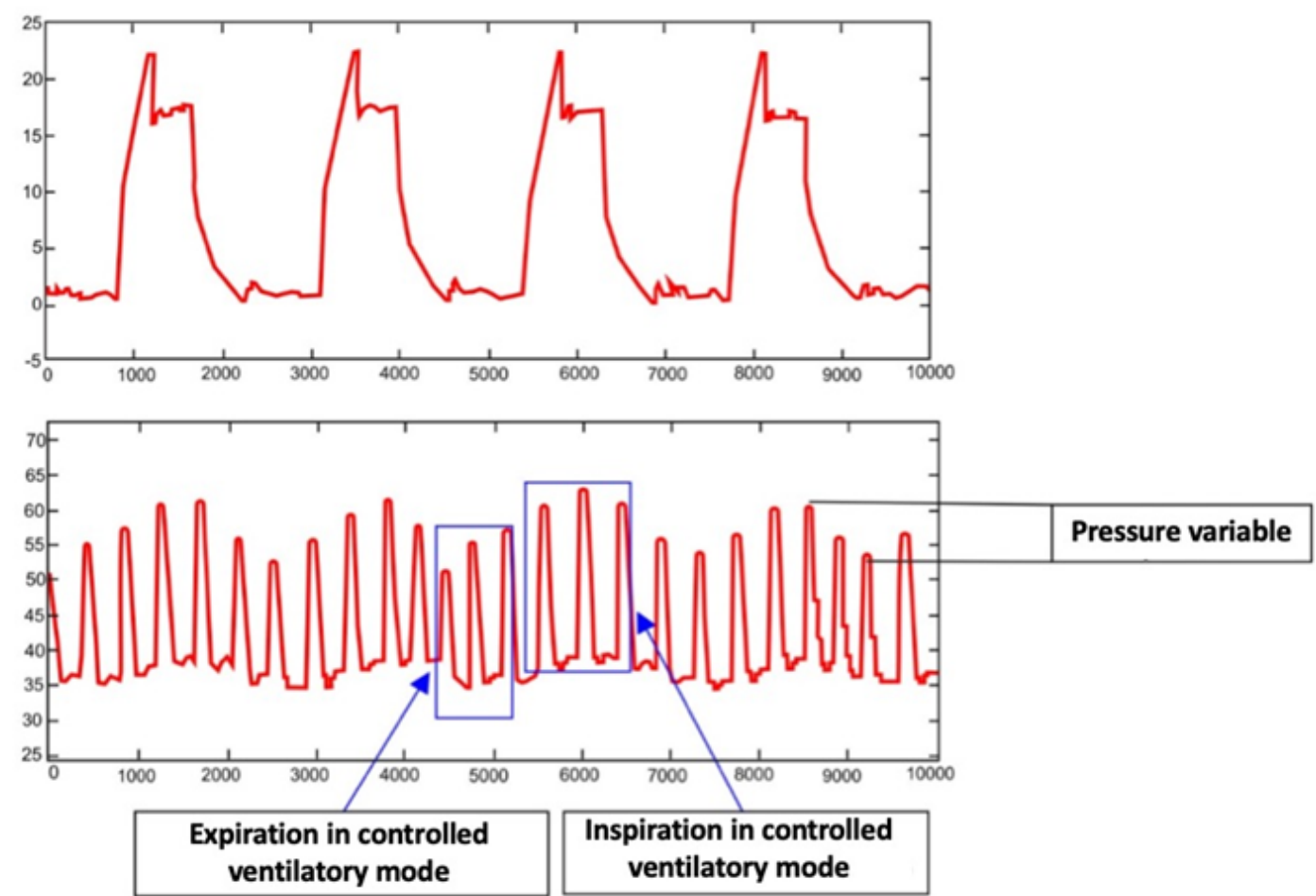

Figure 4 Variability of pulse pressure in the controlled ventilatory cycle, the elevation of the pulse pressure is observed (in the same way the systolic volume or the plethysmography wave) in the inspiratory phase, due to the blood expulsion of the patient. the pulmonary capillaries to distend the alveolus that generate an increase in the ejected stroke volume in those patients who could be responders to volume, likewise a decrease in the pulse pressure in the expiratory phase is observed.

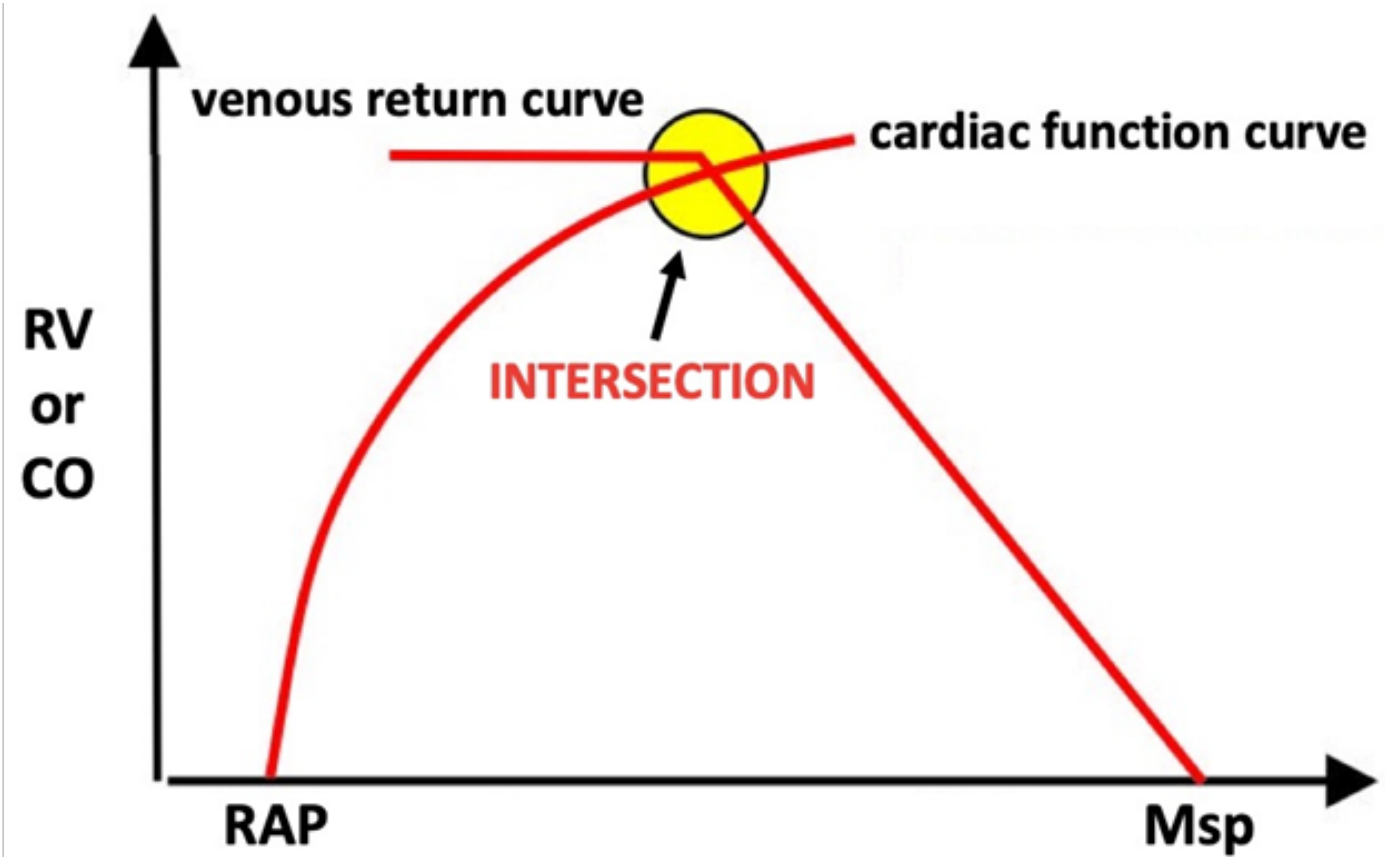

Figure $\mathbf{5}$ This curve shows the right atrial pressure (RAP) and the mean systemic pressure (Msp) on the horizontal axis, related to the venous return (RV) or cardiac output (CO) on the vertical axis, where it is observed that the higher the gradient between the pressure of the left atrium and the average systemic pressure, the greater the volume that returns to the heart (venous return) and therefore the higher the cardiac output, if the average systemic pressure decreases or the right atrial pressure increases, this gradient will be lower and the venous return and cardiac output will decrease. 


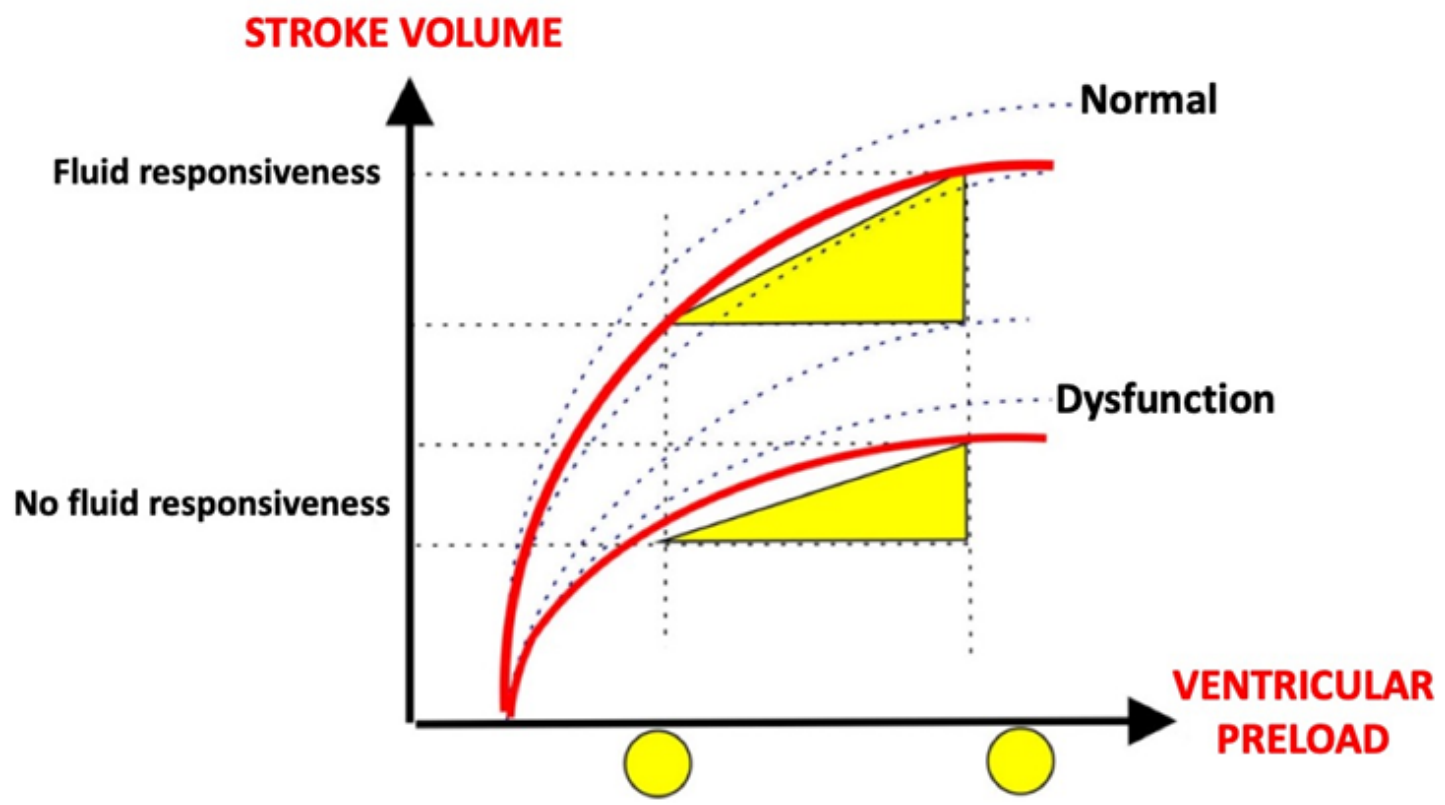

Figure 6 Frank Starling curve, In the preload dependent area, it is observed that small variations in preload induce a significant increase in stroke volume, with a slight increase in transmural pressure and a significant increase in the diastolic dimension of the left ventricle. In the independent preload zone, we observed a minimal (or null) increase in stroke volume after increasing the preload, with a significant increase in transmural pressure and minimal increase in the diastolic dimension of the left ventricle.

Table 5 Limitations in the interpretation of the SVV and PPV. HR, RR ratio; HR, Heart rate; RR, Respiratory frequency

Limitations of the pulse pressure variability, strove volumen variability and arterial elastance

Spontaneous ventilation or Asynchrony with the ventilator.

Tachycardia over 120 beats per minute.

Relation HR: RR; over 4 to I.

Cardiac Arrhythmias or Ventricular Extrasystoles (greater than 3 in 20 seconds).

Right ventricular disfunction

If the patient got all of the above, make an inspiratory pause for 20 seconds

\section{Integration of systolic volume variability}

In 2015 Canneson et al. Conducted a prospective study at the University of Irvine, California, to observe the behavior of VVS in goal-guided therapy in high-risk surgeries. The study consists of 330 patients divided into 2 groups, both taking the arterial line, basing the decision on goal-guided versus non-goal-driven management, based on the algorithm (Figure 7) that is the basis for the decision making in the Operating Room and critical areas, taking as a cornerstone the VVS, with a cut-off point of $8-12 \%$, also takes into account the Cardiac Index (IC) with a cut-off point of $2.5 \mathrm{~L} / \mathrm{min}$, for this takes into account 3 points that are key to tracking the algorithm: ${ }^{31}$

1. Maintenance with Cristaloids at $3 \mathrm{ml} / \mathrm{kg}$, administration of blood products does not affect the protocol.

2. Controlled mechanical ventilation at ideal weight of $8 \mathrm{ml} / \mathrm{kg}$ with positive pressure.

3. Cardiac Monitoring for Auricular Fibrillation surveillance or alterations in the heart rate.

\section{Gasometry}

The analysis of the acid-base balance is another of the utilities of having an arterial line, of the multiple parameters with which gasometry counts depending on the gasometer we have, we must maintain the base acid balance at all times, we can count The lactate product of anaerobic respiration, if greater than $5 \mathrm{mmol} / \mathrm{L}$, associated with a $\mathrm{pH}$ lower than 7.35 and an excess of base greater than 6 $\mathrm{mmol} / \mathrm{L}$, correlates with a mortality of $80 \%{ }^{32}$

But we must ask ourselves: Is the arterial catheter necessary to take gasometries? When I have a Central Venous Catheter, do I need the arterial line for Gasometries? Can Venous Gasometry help me without the need for an Arterial Gasometry? Luciano Gattinoni makes a publication in 2017, where he mentions that venous blood gases are as useful as arterial blood gases, even in peripheral gasometry (Table 6) we can base our management with venous gasometries, emphasizing that venous blood gases are not useful for the effective evaluation of oxygenation, however, we can be guided by our pulse oximetry and only if it is necessary to corroborate it with an arterial 
gasometry, ${ }^{33}$ in addition to that if we have non-invasive monitors that be necessary to aggress the patient to place an intraarterial catheter. offer us the other variables in the case of having a CVC not It would

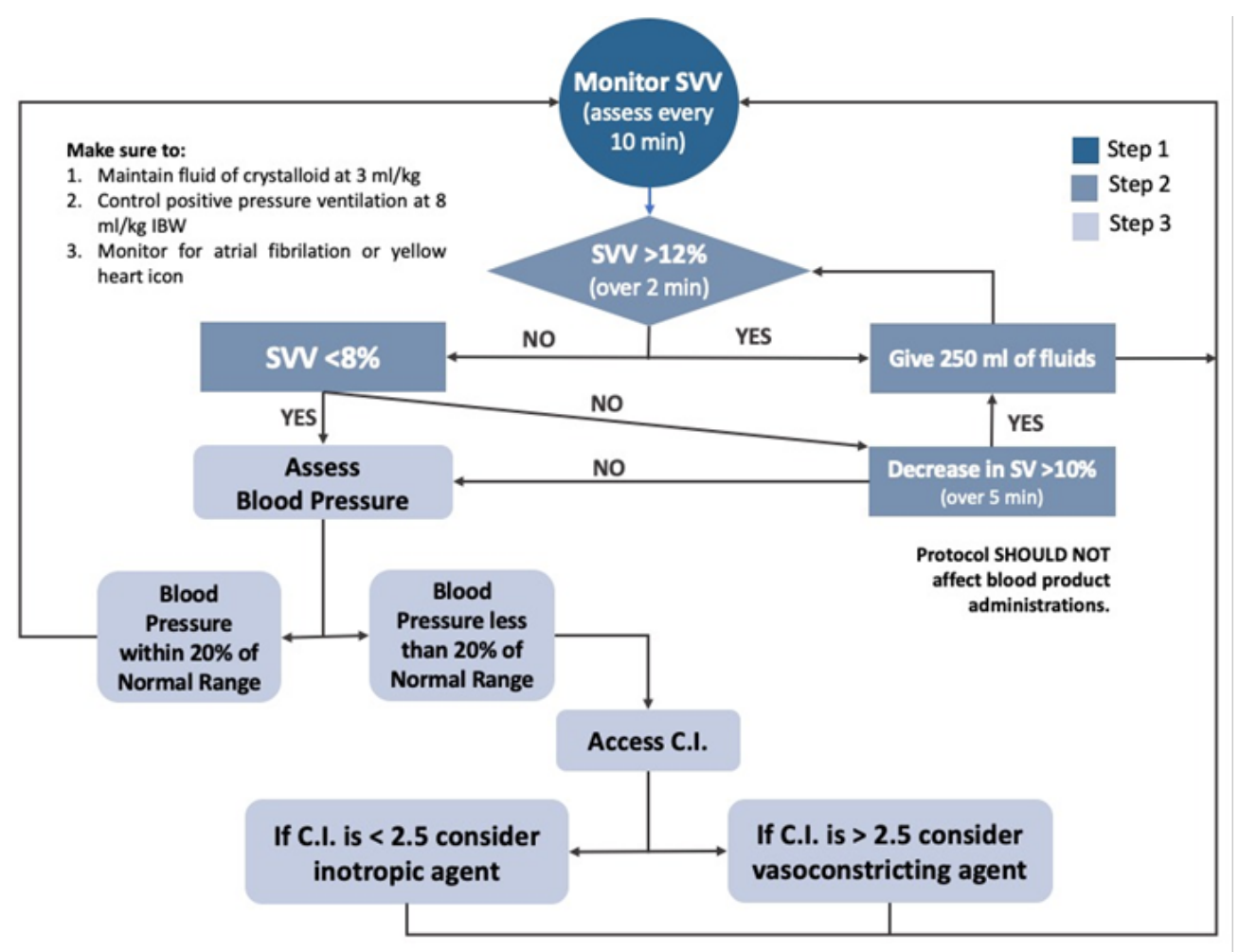

Figure 7 Algorithm for the management of goal-directed therapy. IC, Cardiac Index;VS, Systolic Volume;VVS, Systolic Volume Variability. Taken from Cannesson et al. CriticalCare (2015) 19:261.

Table 6 Correlation between central and peripheral venous blood gases with the arterial. pH, Potential of Hydrogen; $\mathrm{PCO}_{2}$, Partial pressure Carbon dioxide; $\mathrm{HCO}_{3}$, Bicarbonate; $\mathrm{PaO}_{2} / \mathrm{SaO}_{2}$, Differential between partial pressure and Oxygen saturation. * = Use pulse oximeter saturation $\left(\mathrm{SpO}_{2}\right)$

\begin{tabular}{lll}
\hline Variables & Venous Central Gasometry & Venous Periferic Gasometry \\
\hline $\mathrm{pH}$ & $0.03-0.05$ below Arterial & $0.02-0.04$ below Arterial \\
$\mathrm{PCO}_{2}$ & $4-5 \mathrm{mmHg}$ upper the Arterial & $3-8 \mathrm{mmHg}$ upper Arterial \\
$\mathrm{HCO}_{3}$ & Minnimal variation with the arterial & $\mathrm{I}-2 \mathrm{mEq} / \mathrm{L}$ upper Arterial \\
$\mathrm{PaO}_{2} / \mathrm{SaO}_{2}$ & No correlationship & No correlationship* \\
\hline
\end{tabular}

\section{Non-invasive hemodynamic monitoring}

\section{Hemodynamic monitoring}

Non-invasive mycology consists in the measurement of vital signs, which up until a decade ago only included the vital signs: Heart Rate, Respiratory Frequency, Blood Pressure and Body Temperature, if an orotracheal intubation was performed, the expired Carbon Dioxide was quantified $\left(\mathrm{ETCO}_{2}\right)$ and in some surgeries diuresis, but at present it is all that the non-invasive hemodynamic monitoring offers?

With the advancement of technology, we can count on monitors that offer us dynamic and static variables with the estimation of Cardiac Expenditure that have recently been introduced in the country. Next, we will mention some of them, such as Clamping Volume monitors,
Plethysmographic Variability Index, Bioimpedance/Bioreactance and transthoracic echocardiography.

\section{Clamping volume}

Continuous analysis of systemic blood pressure using the clamping method of the radial artery by means of tonometry, as offered by ClearSight (Edwards LifeSciences, USA) CNAP (CNSystems, Austria) as shown in Figure 8. method derived from the pressure in the artery of the finger, analyzing the wave of the pulse contour and supported by plethysmography, by means of an electromechanical sensor, derived in an algorithm, obtaining different variables both dynamic and static (PA, VVS, VPP, GC, IC, RVS) without the need for invasion or taking an arterial line. ${ }^{34,35}$ Its main limitations are: it is a non-calibrated method, it is necessary to use the disposable 
that maintains an average life of 8 hours, edema, peripheral vasoconstriction, hypothermia, hypoxia, among other causes limit its reading, in the perioperative context it has been demonstrated good results, however studies conducted in cardiac surgery and ICU have shown unsatisfactory results. Plethysmographic Variability Index This principle starts from the representation of the pulse oximetry curve with the previously mentioned bases of changes in hemodynamics during inspiration and expiration, processing it in a filter for reading and interpretation based on each supplier's own algorithms. This is the principle with which that Masimo's house bases its hemodynamic variables. The information is extracted and processed by creating 2 indices, the Perfusion Index (IP) and the Plethysmographic Variability
Index (IVP), both are considered dynamic variables and have the physiological basis of the VVS and PPV with a cutoff point for the provider house of $10-15 \%,{ }^{36}$ to advise us on goal-driven management (37). They are available from pulse oximeters that offer these variables and more advanced monitors with different variables not only hemodynamic, when placed on fingers, their limitations are similar to clamping volume: hypothermia, edema, peripheral vasoconstriction, use of disposable (except for Mightysat which is a pulse oximeter with dynamic variables of the house Masimo) and the limitations of the principles of a VVS and a VPP, poor results in Cardiac Surgery and in the Intensive Care Unit.

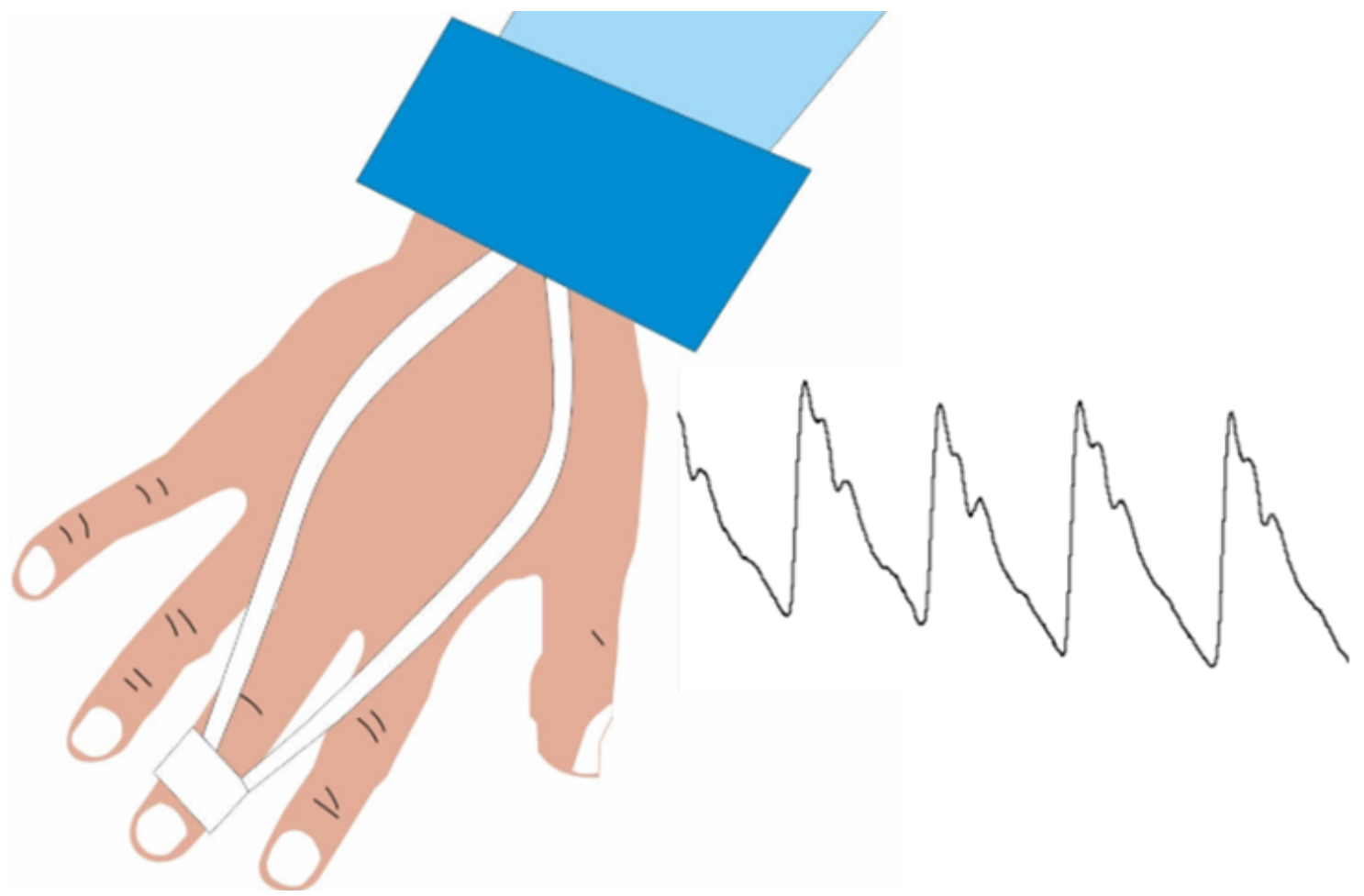

Figure 8 Continuos analysis of the pulse wave by means of the clamping volume. Taken from Kertens et al., NETHJCRITCARE; 2018.

\section{Bioimpedance and biorreactancy}

The bioimpedance is a physical principle that starts from the continuous electrical stimulation to identify the variations of the thoracic impedance produced by each heartbeat, thus being able to identify the phases of the cardiac cycle, the inspiratory and expiratory phase, with the same bases already mentioned, collects the information, interpreted by means of algorithms and expressed in the monitor, ${ }^{38}$ the Nicom house with its Cheetah Medical monitor, has these principles and is currently the one with the most hemodynamic variables, graphs a Frank-Starling curve for the assessment of the challenge of liquids and goal-guided management, it requires the use of disposables that are 4 patches of a transparent adhesive-tape type material with breathing, they can be placed both on the front and on the back depending on the surgical approach or the Anatomical position that the patient is in. It has limitations that the adhesion of disposable patches may be limited by skin disorders, hypothermia, edema, may alter their interpretation, is the one that has shown better results in Cardiac surgery and in the Intensive Care Unit.

\section{Integration of reading of non-invasive cardiac output monitors}

In 2015 in the journal of British Journal of Anesthesia Saugel et al., They perform a meta-analysis comparing the different types of non-invasive monitors found in the market, clamping volume, Pletismographic Variability Index, Bioimpedance, Bioreactance, where they conclude that they can present up to an error in the measurement of $2 \mathrm{~L} / \mathrm{min}^{39}$ but here we must remember 2 things: One is that the Lung Artery Catheter also has an inaccuracy in the measurement of Cardiac Expenditure of up to 30\% and the second is that as says Michael R. Pinsky, there is no normal cardiac output, this GC is the one that fits our hemodynamic needs, therefore the recommendation is made to measure the $\mathrm{GC}$ and its variables prior 
to the anesthetic induction and take the trends of these, in the end Saugel finishes his study saying that more studies are needed to know exactly the behavior of these monitors in different clinical scenarios.
In Figure 9 we propose a diagnostic approach for the patient in shock of unidentified cause through hemodynamic monitoring with noninvasive cardiac output.

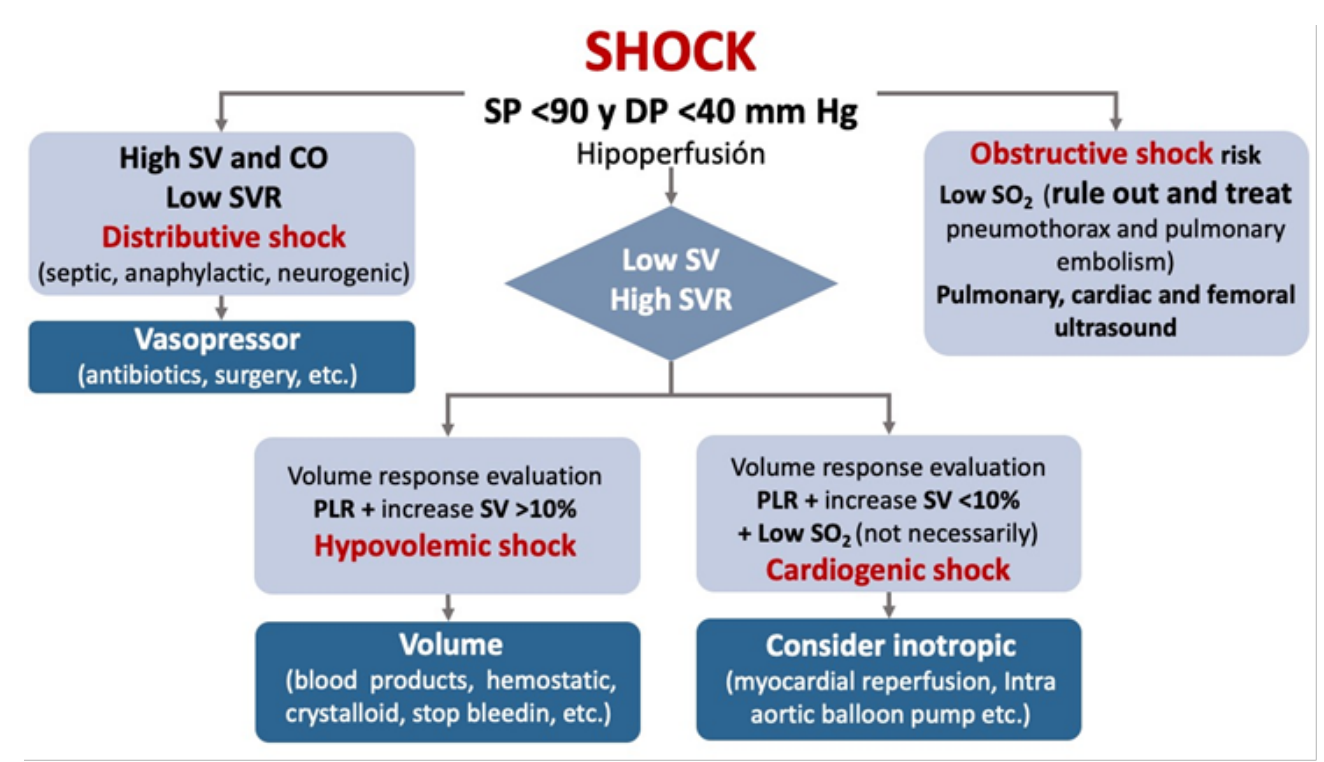

Figure 9 Diagnostic approach to unidentified shock with continuous non-invasive cardiac output.

\section{Transthoracic ultrasound}

One of the most significant advances in the field of medicine is the evolution of Ultrasound, with this the realization of Echocardiograms, the placement of vascular accesses, having an immense impact on patient safet|y, being able to consider the 5th pillar of our physical exploration, ${ }^{40}$ so that it is not only available to the Radiologist or the Cardiologist for the realization of these, it is worth mentioning Dr. Miguel Ángel García Fernández, a pioneer in the teaching of Non Cardiologists for the interpretation of it, where he says that no it is about replacing the Cardiologist for the realization of this, if not to give a benefit to the patient, when performing quantitative and semiquantitative studies, that guide us to an opportune diagnosis and effective treatment. ${ }^{41}$

There are several windows on which we can base our identification of problems:

Paraesternal long axis: we can observe the left ventricular outflow tract (LVOT). Apical 4 cameras: Here we will obtain the Integral Time Velocity (ITV) of the LVOT, capacity of the excursion of the valves in systole, both mitral (MAPSE) and tricuspid (TAPSE), we will also observe the pericardial sac in case of a pericardial effusion or instability by tamponade.

Subcostal: This window serves to observe the Vena Cava Inferior (VCI) to measure its diameter in inspiration and expiration, evaluation of its collapsibility to guide our water management, ${ }^{42}$ with a cut-off point of $12-20 \%$ for patients with probable response to volume. ${ }^{43}$

Suprasternal: in case of suspected dissection or large vessel aneurysm.

Neck: we can add the measurement of the Internal Jugular Vein with the measurement of its inspiratory and expiratory diameter, in case of not being able to obtain the subcostal window or in the case of being in a surgery and that it is difficult to access it, with the same end as in the IVC, presents a cut-off point of $13-25 \%$ for patients responding to water therapy. ${ }^{44,45}$ With these windows a trained doctor for the realization of ultrasound can obtain a hemodynamic workshop in a time of 10 minutes, with static and dynamic variables, such as: Cardiac Output, Systolic Volume, LV Ejection Fraction, Central Venous Pressure, Index of Collapse of the inferior vena cava and internal jugular vein, as well as direct visualization of myocardial behavior in various clinical scenarios: myocardial contractility, myocardial thickness, left atrial size, right ventricular dilatation, pericardial effusion. ${ }^{46} \mathrm{~A}$ non-invasive method It is fundamental the training of the doctor for the capacity of the use of critical ultrasound in the perioperative context.

\section{Estimated continuous cardiac output}

The estimated continuous cardiac output is a novel method that starts from the beginning of the transit time of the pulse wave (PWtt) ${ }^{47}$ which takes as an initial starting point the cusp of the $\mathrm{R}$ wave of the cardiac bypass monitor and as the end point the start of the pulse pressure wave in the plethysmography, integrating the blood pressure in the equation, taken in an invasive or non-invasive way, so that the lower the PWtt, the higher the patient's GC and vice versa, the values of VS and GC, with a reported variation up to $2.6 \mathrm{~L} / \mathrm{min}$ in the $\mathrm{GC}$ figure that can be reduced if it is calibrated with echocardiography or other methods such as transpulmonary thermodilution or catheterization to the pulmonary artery, losing the advantage of being non-invasive in the last two cases . It requires 3 to 10 minutes for reading, there are case reports of its use in ICU patients and transplant surgery, ${ }^{48}$ it has the advantage of not requiring consumables per patient, of being completely non-invasive and of showing tendencies, as main disadvantages there is a reading failure in patients with abnormal heart rhythms (arrhythmias, pacemakers), cardiac tamponade, transoperative cardiac surgery and the use of extracorporeal circulation pump (Figure 10). 


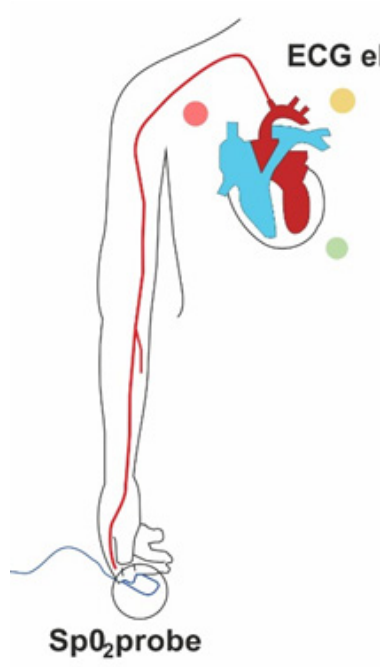

ECG

Aortic root pressure

Radial arterial pressure

Differentiated pulse oximeter wave

Pulse oximeter wave

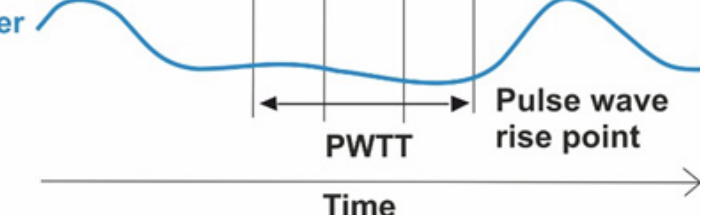

Figure 10 Estimated continuous cardiac output.

\section{Discussion}

Perioperative hemodynamic monitoring is essential for the monitoring of vital parameters and decision making, thus ruling out differential diagnoses, obtaining a precise diagnosis in time and offering appropriate treatment to the patient. Traditionally for decision-making in the critical patient, invasive monitoring has been chosen with the placement of a Lung Artery Catheter, a moderately invasive monitoring with a Central Venous Catheter, or minimally invasive with the taking of an arterial line, Many times without criteria of high patient invasion or without taking into account all the hemodynamic variables that can offer us the different types of alternatives that we currently have, we must remember that our principle as a doctor is not to harm the patient, as mentioned in the Consensus on Hemodynamic Monitoring and Shock of 2014, do not base our goal-guided management on the Pulmonary Artery Occlusion Pressure or the Central Venous Pressure, use dynamic variables, always use one more for decision-making, when in doubt apply a fluid challenge, remembering that fluid therapy is not safe considering the principles of Malbrain, Pinsky and Paul Marik ${ }^{49,50}$ and that the order of the factors does alter the patient's result, so always follow algorithms and choose the treatment of choice, be it vasopressor, inotropic or fluid therapy, in the different clinical scenarios, ${ }^{51}$ because the more evidence we have at the time of making a diagnosis, you can offer the patient the treatment of choice.

In 2015 J.L. Vincent and colleagues published the article they called the Consensus of 12 (this is due to the 12 authors involved), where they mention reducing the invasion, even sacrificing monitoring precision with the monitoring of trends, the use of arterial pressure non-invasive in semi-continuous or continuous by short episodes, to try to minimize the invasion, mark 2 patterns of attitude the reactive and non-reactive doctor, based on the hemodynamic optimization, reactive is that doctor who waits for the changes for the correction of the variables and the proactive one is the one that seeks to optimize these variables being in constant maintenance and search of the pro of the patient. ${ }^{52}$
J.L. Teboul in 2016 publishes a panel of experts with the primary objective of decreasing the invasion of the critical patient, exhorting the use of non - invasive cardiac monitors or decreasing the use of Swan - Ganz Catheter, leaving in its algorithm the use of CAP only for patients with Severe Respiratory Distress Syndrome, that patient does not improve with the help of primary monitoring or when no more monitoring is available, based on this they conclude with the phrase less is more, less monitoring can offer us the same benefit as invasive monitoring, as long as the knowledge and adequate variables are available, ${ }^{53}$ but we must remember that if it cannot be measured, I cannot evaluate it, therefore patient monitoring should be dynamic (Figure 11), can start with non-invasive monitoring and end in an invasive, always looking for the benefit of the patient with the least possible damage.

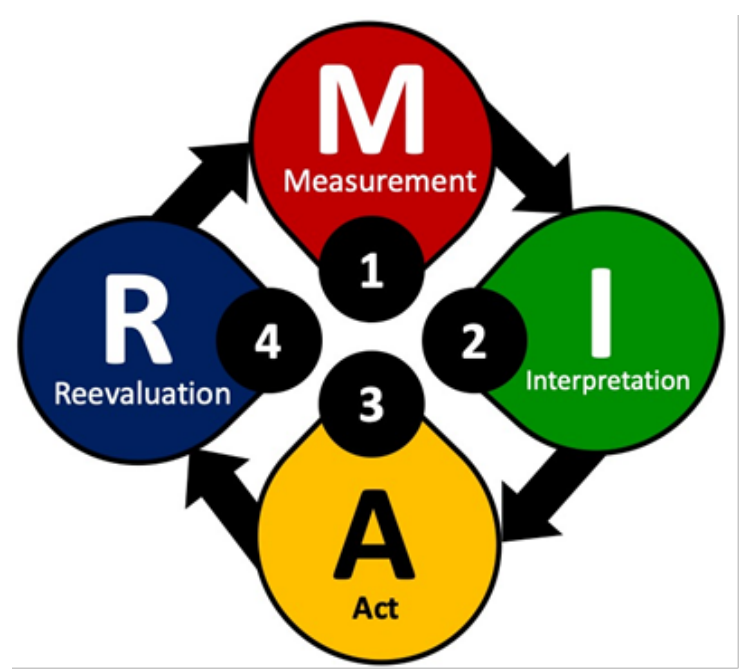

Figure I I Proposal of critical patient interventions that includes reevaluation as an important point to observe the response to our therapy. ${ }^{18}$ 


\section{Conclusion}

In recent years the evolution in hemodynamic monitoring has been considerable in such a way that nowadays we can have dynamic variables without the need to invade the patient. New algorithms have emerged based on parameters such as VPP, VVS, GC, IC, Blood Pressure, preload predictors that have implemented non-invasive Cardiac Surveillance monitors, pocket or portable ultrasounds for measurements and decision-making without the risk of placing intravascular accesses. This is really attractive for the management of the critical and non-critical patient, decreasing the patient's invasion, we must take the attitude of less is more and that there is no monitor that fits in all patients, this is where the clinician must understand that technology advances in all areas and therefore as doctors we are not exempt from this, understanding the advantages and disadvantages that this offers us in the hemodynamic management in the perioperative period.

\section{Conflicts of interst}

All authors declare no conflict of interest.

\section{Financing}

The present article did not receive any kind of financing.

\section{References}

1. Álvarez-Reséndiz GE, Ochoa-Gaitán G, Velazco-González JG, et al. Monitoreo Anestésico Básico. CMA. 2013;36(Supple 1):S95-S100.

2. Saugel B, Bendjelid K, Critchley LA, et al. Journal of Clinical Monitoring and Computing 2017 end of year summary: cardiovascular and hemodynamic monitoring. Journal of Clinical Monitoring and Computing. 2018:2.

3. Alhashemi JA, Cecconi M, Hofer CK. Cardiac output monitoring: an integrative perspective. Critical Care. 2011;15:214.

4. Pinsky MR. Functional haemodynamic monitoring. Curr Opin Crit Care. 2014;20:288-293.

5. Pearse R, Harrison D, MacDonald N, et al. Effect of a Perioperative, Cardiac Output-Guided Hemodynamic Therapy Algorithm on Outcomes Following Major Gastrointestinal Surgery A Randomized Clinical Trial and Systematic Review. JAMA. 2014;311(21):1-10.

6. Makaryus R, Miller TE, Gan TJ. Current concepts of fluid management in enhance drecovery pathways. British Journal Anaesthesia. 2017;1-8.

7. Fein AM, Goldberg SK, Walkenstein MD. Is pulmonary artery catheterization necessary for the diagnosis of pulmonary edema? $\mathrm{Am}$ Rev Resp Dis. 1984;129(6):1006-1009.

8. Marik PE. Obituary: pulmonary artery catheter 1970 to 2013. Annals of Intensive Care. 2013;3:38.

9. Lennon M. Pulse Contour Analysis and Trans pulmonary Thermodilution. Australasian Anaesthesia. 2003;163-172.

10. Monnet X, Teboul JL. Trans pulmonary thermodilution: advantages and limits. Monnet and Teboul Critical Care. 2017;21:147.

11. Marik P, Cavallazi R. Does the Central Venous Pressure Predict Fluid Responsiveness? An Updated Meta-Analysis and a Plea for Some Common Sense. Crit Care Med. 2013;41(7):1774-1782.

12. Berlin DA, Bakker J. Starling curves and central venous pressure. Berlin and Bakker Critical Care. 2015:19:55.

13. De BackerD, Vincent JL. Should we measure the central venous pressure to guide fluid management? Ten answers to 10 questions. De Backer and Vincent Critical Care. 2018;22:43.

14. Eltzschig HK, Rosenberger P, Löffler M, et al. Impact of Intraoperative Transesophageal Echocardiography on Surgical Decisions in 12,566 Patients Undergoing Cardiac Surgery. Ann Thorac Surg. 2008;85(3):845-53.

15. Kaplan A, Mayo PH. Echocardiography performed by the pulmonary, Critical care medicine physician. Chest. 2009;135:529-535.

16. Hahn TR, Abraham T, Adams SM, et al. Guidelines for Performing a Comprehensive Transesophageal Echocardiographic Examination: Recommendations from the American Society of Echocardiography and the Society of Cardiovascular Anesthesiologists. J Am Soc Echocardiogr. 2013;26:921-964.

17. Cecconi M, De Backer D, Antonelli M, et al. Consensus on circulatory shock and hemodynamic monitoring. Task force of the European Society of Intensive Care Medicine. Intensive Care Med. 2014;40(12):17951815

18. Nieto-Pérez OR, Sánchez-Díaz JS, Solórzano-Guerra A, et al. Fluidoterapia intravenosa guiada por metas. MedInt Méx. 2019;35(2):235-250.

19. Tonetti T, De Cassai A, Ori C. Acute is chemia of the thumbcaused by radial arterycannulation. Intensive Care Med. 2018;44:656-657.

20. De Backer D, Heenen S, Piagnerelli M, et al. Pulse pressure variations to predict fluid responsiveness: influence of tidal volume. Intensive Care Med. 2005;31:517-523.

21. Reuter DA, Bayerlein J, Goepfert MS. Influence of tidal volume on left ventricular stroke volume variation measured by pulse contour analysis in mechanically ventilated patients. Intensive Care Med. 2003;29:476480 .

22. Rewa O, Bagshaw SM. Principles Fluid Management. Critical Care Clinics. 2015;31(4):785-801.

23. Baker KH. Venousreturn: implications for understanding clinical hemodynamics. ASA Refresher Courses Anesthesiol. 2004;32:9-17.

24. Marik PE, Monnet X, Teboul JL. Hemodynamic parameters to guide fluid therapy. Ann Intensive Care. 2011;1(1):1.

25. Marik PE, Cavallazzi R, Vasu T. Stroke volume variation and fluid responsiveness. A systematic review of the literature. Crit Care Med 2009;37:2642-647.

26. Mallat J, Meddour M, Durville E, et al. Decrease in pulse pressure and stroke volume variations after mini-fluid challenge accurately predicts fluid responsiveness. Br J Anaesth. 2015;115(3):449-456.

27. Guyton A. Determination of cardiac output by equating venous return curves with cardiac response curves. Physiol Rev. 1955;35:123.

28. Guyton A. Regulation of cardiac output. N Engl J Med. 1967;277:805.

29. Woodcock TE, Woodcock TM. Revised Starling equation and the glycocalyx model of trans vascular fluid exchange: an improved paradigmfor prescribing intravenous fluid therapy. BJA. 2012;108(3) 384-94.

30. Michard F, Teboul JL. Predicting fluid responsiveness in ICU patients: a criticalan alysis of the evidence. Chest. 2002;121:2000-8. 19.

31. Cannesson M, Ramsingh D, Rinehart J, et al. Perioperative goal-directed therapy and postoperative outcomes in patientsundergoinghigh-risk abdominal surgery: a historical-prospective, comparative effectiveness study. Critical Care. 2015:19:261.

32. Phypers B, Pierce T. Lactatephysiology in health and disease. Continuing Education in Anaesthesia, Critical Care \& Pain. 2006;6(3):128-132. 
33. Gattinoni L, Pesenti A, Matthay M. Understanding blood gas analysis. Intensive Care Med. 2018;44(1):91-93.

34. Thiele RH, Bartels K, Gan TJ. Cardiac output monitoring: a contemporary assessment and review. Crit Care Med. 2015;43:177-185.

35. Saugel B, Dueck R, Wagner JY. Measurement of blood pressure. Best Pract Res Clin Anaesthesiol. 2014;28:309-322.

36. Cannesson M, Desebbe O, Rosamel P. Platvariabilityindexto monitor the respiratory variations in the pulse oximeterplethysmo graphicwave form amplitude and predict fluid responsiveness in the operating theatre. Br J Anaesth. 2008;101(2):200-206.

37. Monnet X, Pinsky MR. Predicting the determinants of volume responsiveness. Intensive Care Med. 2015;41:354-356.

38. Marik PE. Noninvasive cardiac output monitors: a state-of the-art review. J Cardiothorac Vasc Anesth. 2013;27:121-134.

39. Saugel B, Cecconi M, Wagner JY, Reuter DA. Noninvasive continuous cardiac output monitoring in perioperative and intensive care medicine. Br J Anaesth. 2015;114:562-575.

40. Narula J, Chandrashekhar Y, Braunwald E. Time toAdd a Fifth Pillar to Bedside Physical Examination Inspection, Palpation, Percussion, Auscultation, and Insonation. JAMA Cardiology. 2018:2.

41. García Fernández MA. ¿Es posible entrenar a no cardiólogos para realizar ecocardiografía? Rev Esp Cardiol. 2014;67(3):168-170.

42. Boyd JH, Sirounis D, Maizel J, Slama M. Echocardiography as a guide for fluid management. Critical Care. 2016;20:274.

43. Carrillo Esper R, Tapia Velasco R, Galvan Talamantes Y, et al. Evaluación de la precarga y respuesta a volumen mediante ultrasonografía de la vena cava. Rev Asoc Mex Med Crit y Ter Int. 2015;29(2):105-112.

44. Ma $\mathrm{G}$, Hao $\mathrm{G}$, Yang $\mathrm{X}$, et al. Internal jugularve in variability predicts fluid responsiveness in cardiac surgical patients with mechanical ventilation. Ann Intensive Care. 2018;8:6.
45. Guarracino F, Ferro B, Forfori F, et al. Jugular vein dispensability predicts fluid responsiveness in septic patients. Critical Care. 2014;18:647.

46. Porter TR, Shillcutt, SK, Adams MS, et al. Guidelines for the Use of Echocardiography as a Monitor for Therapeutic Intervention in Adults: A Report from the American Society of Echocardiography. J Am Soc Echocardiogr. 2015;28:40-56.

47. Yamada Y, Sugo J. Takeda, et al. Verification of a non-invasive continuous cardiac output measurement method based on the pulsecontour analysis combined with pulse wave transit time. Eur $J$ Anaesthesiol. 2010;47:3AP5-AP9.

48. Su BC, Tsai YF, Chen CY. Cardiac output derived from arterial pressure waveform analysis in patients undergoing liver transplantation: Validity of a third-generation device. Transplant Proc. 2012;44:424-428

49. Marik PE. Fluid responsiveness and the six guiding principles of fluid resuscitation. Crit Care Med. 2016;44:1920-1922.

50. Malbrain M, Regenmortel NV, Saugel B, et al. Principles of fluid management and stewardship in septic shock: itis time to consider the four D's and the four phases of fuid therapy Ann. Intensive Care. 2018;8:66

51. Rivers E. Early goal-directed therapy in the treatment of severe sepsis and septic shock. N Engl J Med. 2001;345:1368-1377.

52. Vincent JL, Pelosi P, Pearse P, et al. Perioperative cardiovascular monitoring of high-risk patients: a consensus of 12. Critical Care. 2015;19:224.

53. Teboul JL, Saugel B, Cecconi M, et al. Less invasive hemodynamic monitoring in critically ill patients. Intensive Care Med. 2016;42:1350 1359. 